\title{
EFFECT OF DISTANCE ON LOCAL MAGNITUDES FOUND FROM STRONG-MOTION RECORDS
}

\author{
By Paul C. Jennings and Hiroo Kanamori
}

\begin{abstract}
Values of local magnitude $M_{\mathrm{L}}$, are calculated from 56 strong-motion accelerograms recorded in the Imperial Valley earthquake of 15 October 1979 according to procedures developed earlier (Kanamori and Jennings, 1978). These data, plus similar data from the San Fernando earthquake of 9 February 1971 and additional, less numerous data from several other California earthquakes, are used to investigate the use of different measures of distance in near-field determinations of $M_{L}$ : this investigation has relevance for similar uses of distances in determining seismic design criteria. In addition, the consistency of the values of $M_{\mathrm{L}}$ found from the strong-motion data is examined from the viewpoint of assessing the need for any correction in the standard attenuation curve, $-\log _{10} A_{0}(\Delta)$.

It was found that the most consistent values of $M_{L}$ result when distance is measured to the closest point on the surface trace of the fault if a site lies within a circle with diameter equal to the extent of faulting and centered on the center of faulting (center of energy release). Outside this circle, the distance measured to the center of the circle is recommended.

A consistent trend in the values of $M_{L}$ found from strong-motion records is seen in the data. The values start, at zero distance, at essentially the far-field value and then decrease to $-1 / 4$ unit at about $20 \mathrm{~km}$. Then they rise to $+1 / 4$ unit at 50 to $60 \mathrm{~km}$. A smooth revision to the standard attenuation curve is presented which removes this systematic trend.
\end{abstract}

\section{INTRODUCTION}

The local magnitude, $M_{L}$, was initially introduced by Richter (1935) as a relative measure of earthquakes in southern California. As originally defined, $M_{L}$ is determined from the amplitude of motion recorded by the standard Wood-Anderson seismograph, which has a period of $0.8 \mathrm{sec}$, a damping constant of 80 per cent of critical, and a magnification of 2800 . The period and damping of the Wood-Anderson instrument are such as to make it sensitive to ground motion in the period range of greatest engineering interest (typically 0.2 to $3 \mathrm{sec}$ ). This feature, plus the fact that $M_{L}$ is determined from ground motions closer to the source than is the case for other magnitudes, means that $M_{L}$ is of particular interest for most engineering applications, including the determination of seismic design criteria for major projects.

Kanamori and Jennings (1978), Jennings and Kanamori (1979), Espinosa (1980), and Boore (1980) have used strong-motion accelerograms obtained at short epicentral distances to determine the local magnitude. Whether seismograms from the Wood-Anderson instruments are used directly, or if synthetic Wood-Anderson seismograms are used as in Kanamori and Jennings (1978), the basis of the calculation of $M_{L}$ from the maximum Wood-Anderson response is the amplitude attenuation curve (as a function of distance) constructed by Richter (1935) for a reference event. However, Richter's (1935) curve is given only for $\Delta \geqq 25 \mathrm{~km}$. At distances $\Delta$ $\leqq 25 \mathrm{~km}$, the standard Wood-Anderson seismographs go off scale for events with $M_{L} \geqq 4.5$; no reliable amplitude measurements can be made on this instrument at 
$\Delta \leqq 25 \mathrm{~km}$ for events large enough to have much engineering significance. This is one of the reasons for using the accelerograph data in the studies mentioned above. Later, Gutenberg and Richter (1942) extended the attenuation curve to the distance range $0 \leqq \Delta \leqq 30 \mathrm{~km}$; however, the data for this range were obtained by $4 \times$ torsion

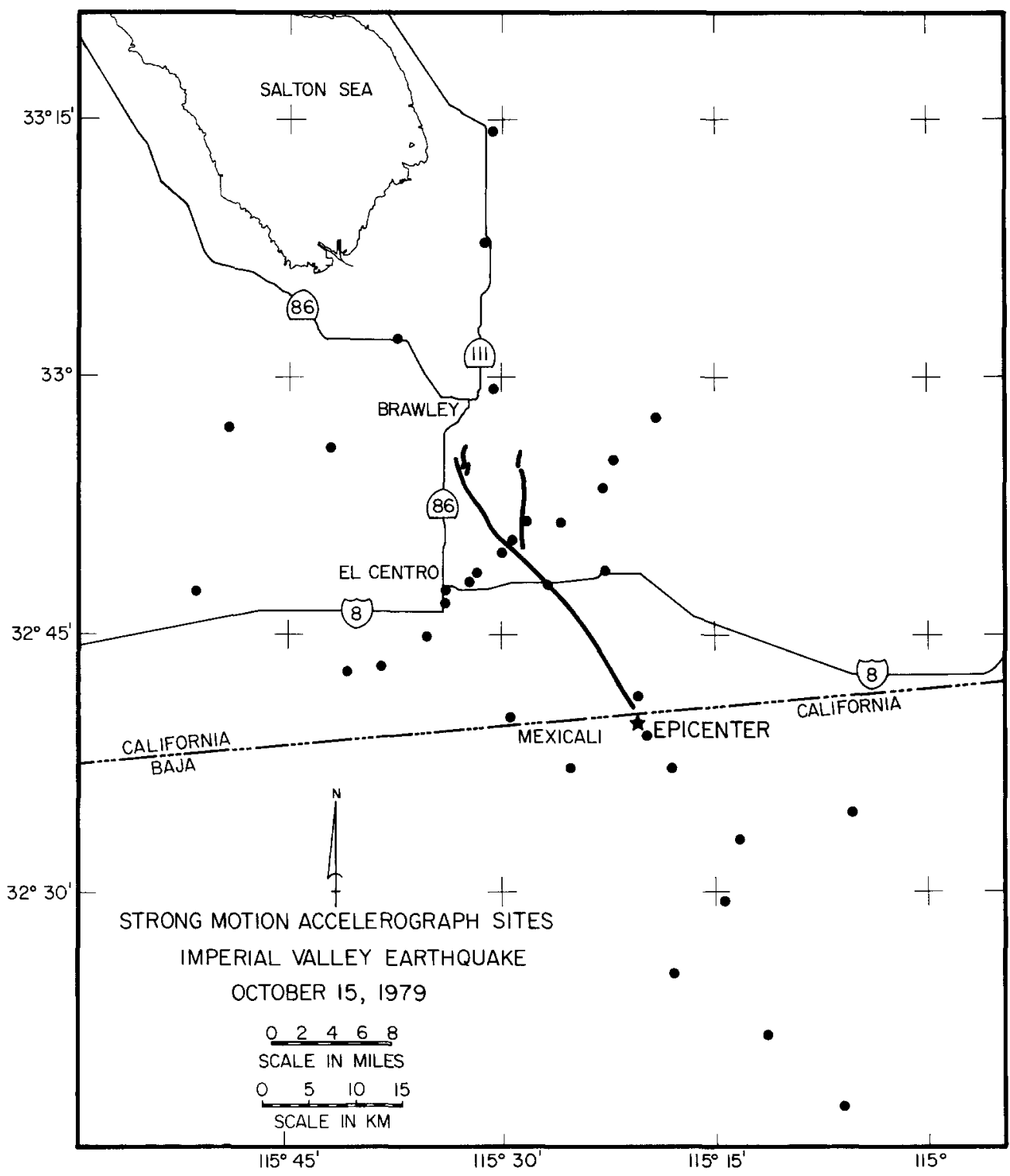

FIG. 1. Location of strong-motion accelerographs recording the Imperial Valley earthquake of 15 October 1979. A few more distant accelerographs triggered, but their records were very small and were not used in this study. The heavy line indicates the surface faulting.

seismometers whose response is different from the standard Wood-Anderson seismograph (the period is $10 \mathrm{sec}$ and the damping near critical). Thus, the determination of $M_{L}$ at short distances, particularly at $\Delta \leqq 25 \mathrm{~km}$, requires some caution.

The extended attenuation curve is that which is tabulated in Richter (1958) and was used by us in our earlier studies [Kanamori and Jennings (1978); Jennings and Kanamori (1979)]. 
Another related problem concerns the measure of distance. The fact that the strength of shaking typically reduces with distance is of great importance in the determination of earthquake-resistant design criteria. In practice, the measure of distance used is not too significant if the site is relatively far away from the potential earthquake source; however, the definition of distance becomes important when the distance from the site to the fault is comparable to the postulated length of faulting or depth of focus. It is in the near-field, of course, where seismic design criteria are the most stringent and expensive to implement. For sites in the near-field, different

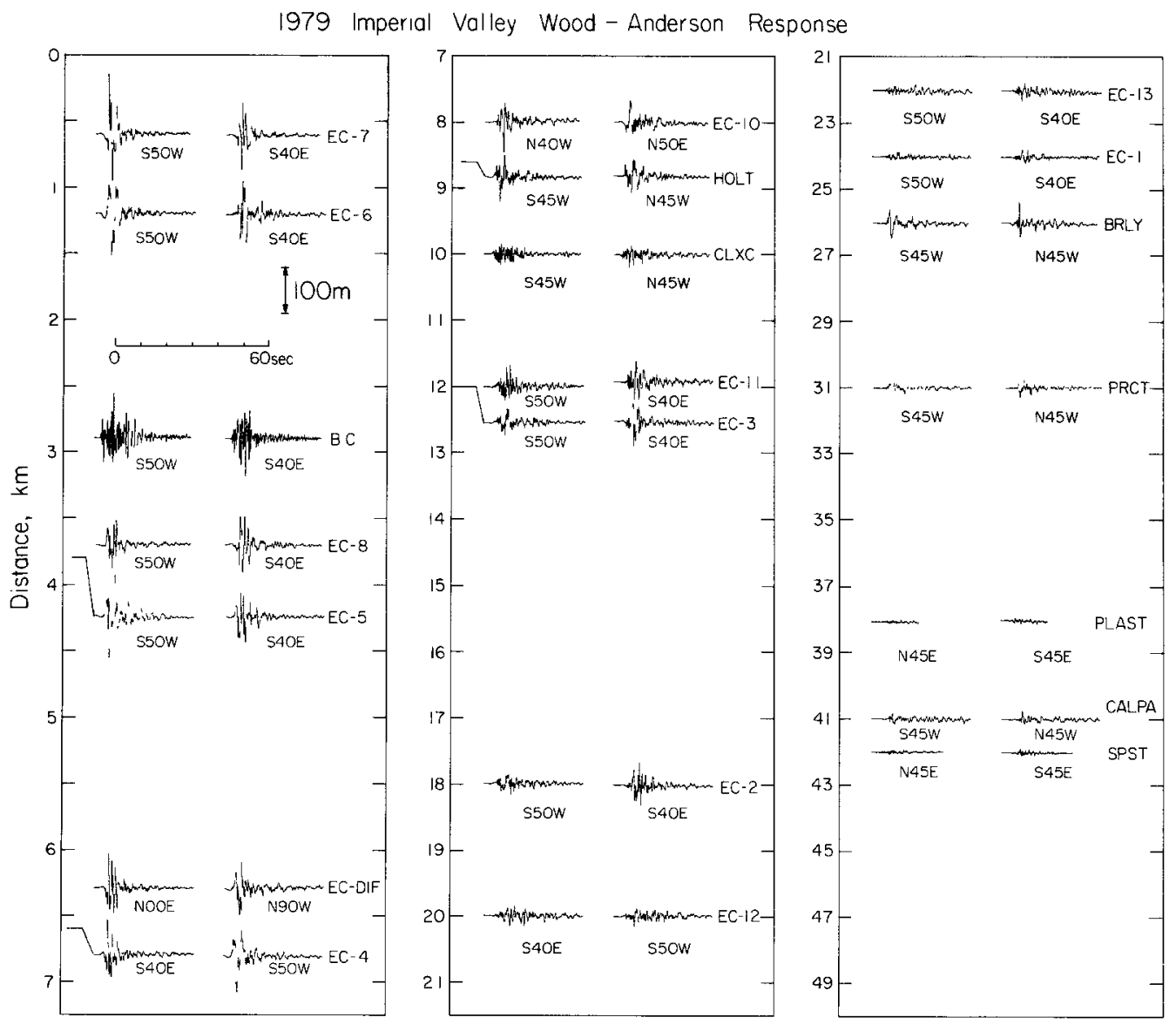

FIG. 2. Synthetic Wood-Anderson seismograms calculated from accelerograms from the Imperial Valley earthquake of 15 October 1979. The distance is from the fault, as discussed in the text. All seismograms are plotted to the time and amplitude scales shown in the upper left corner of the figure.

measures of distances can result in significantly different estimates of the expected strength of ground shaking, and there exists some controversy over the most appropriate measure. The studies of attenuation of ground motion with distance which are used to make estimates of strong ground motion for design implicitly assume that the magnitude computed for a given earthquake is the same regardless of the distance, aside from random statistical fluctuations. In particular, if local magnitude is used, the assumption is made that records from Wood-Anderson seismographs, when used with the selected measure of distance and the standard attenuation curve for $M_{L}$, give a value of $M_{L}$ that is independent of distance, even 
in the near-field. Again, random statistical fluctuations about a mean value are inevitable, but systematic trends with distance are assumed to be absent.

In order to investigate both the amplitude attenuation curve at short distances and the best measure of distance to be used for the study of the attenuation of strong ground motion, we analyzed an extensive set of strong-motion records
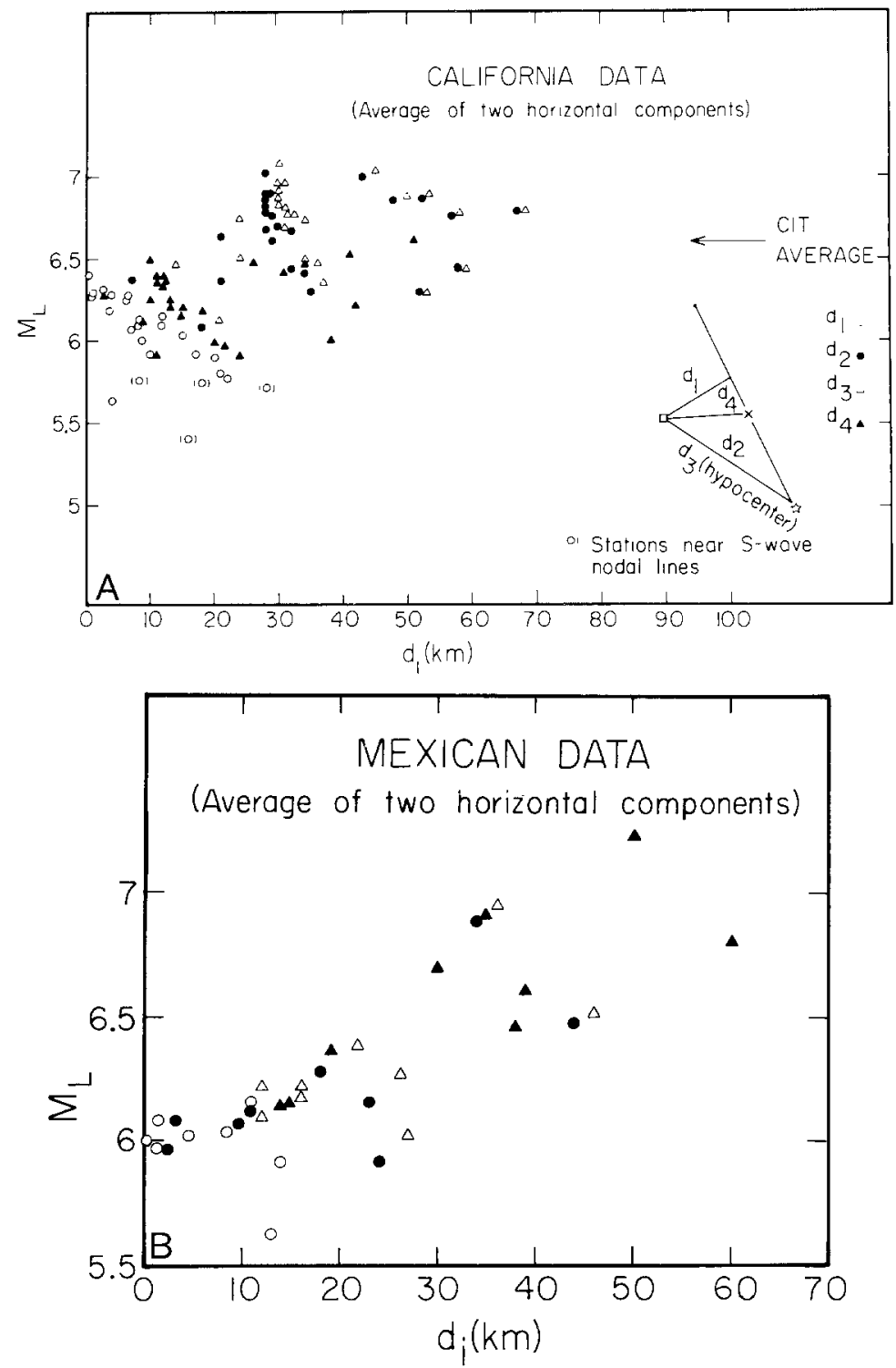

FIG. 3. Values of $M_{L}$ for the Imperial Valley earthquake of 15 October 1979. Four measures of distance are used: $d_{1}$, closest distance to the fault; $d_{2}$, epicentral distance; $d_{3}$, hypocentral distance; and $d_{4}$, distance to center of faulting. (a) California data. (b) Mexican data. Data in parentheses are near-nodal lines for $\mathrm{SH}$ motion.

obtained for the Imperial Valley earthquake of 15 October 1979. For this earthquake, the accelerograph sites are particularly well located to study these two problems. In addition, we have supplemented this data set with those from the 1971 San Fernando earthquake and several other earthquakes in California. 
TABLE 1

Local Magnitude, $M_{L}$, For the 1979 Imperial Valley Earthquake Determined from StrongMotion ACcelerograms-California Data

\begin{tabular}{|c|c|c|c|c|c|c|c|c|c|c|c|c|}
\hline Ref. No.* & Station & Component & $\begin{array}{c}P P / 2 \dagger \\
(\mathrm{m})\end{array}$ & $\begin{array}{c}T 4 \\
(\mathrm{sec})\end{array}$ & $\begin{array}{c}d_{1} \\
(\mathrm{~km})\end{array}$ & $\boldsymbol{M}_{L_{1}}$ & $\begin{array}{c}d_{2} \\
(\mathrm{~km})\end{array}$ & $M_{L_{2}}$ & $\begin{array}{c}d_{3} \\
(\mathrm{~km})\end{array}$ & $M_{L_{3}}$ & $\begin{array}{c}d_{4} \\
(\mathrm{~km})\end{array}$ & $M_{L_{4}}$ \\
\hline \multirow[t]{2}{*}{ IIZ001 } & IMP BLD FF & N02E & 43.1 & 1.3 & 7.00 & 6.07 & 29.0 & 6.69 & 31.0 & 6.77 & 13.0 & 6.19 \\
\hline & & S88E & 57.3 & 1.9 & & 6.20 & & 6.82 & & 6.90 & & 6.32 \\
\hline \multirow[t]{2}{*}{ IIZ003 } & El Centro 7 & S50W & 117.0 & 1.9 & 0.60 & 6.47 & 28.0 & 7.09 & 30.0 & 7.17 & 10.0 & 6.57 \\
\hline & & S40E & 75.8 & 1.0 & & 6.28 & & 7.00 & & 6.90 & & 6.38 \\
\hline \multirow[t]{2}{*}{ IIZ004 } & El Centro 6 & $\mathrm{~S} 50 \mathrm{~W}$ & 75.5 & 3.2 & 1.20 & 6.28 & 28.0 & 6.90 & 30.0 & 6.98 & 11.0 & 6.40 \\
\hline & & S40E & 71.0 & 2.0 & & 6.25 & & 6.87 & & 6.95 & & 6.37 \\
\hline \multirow[t]{2}{*}{ IIZ005 } & Bonds Corner & S50W & 78.2 & 0.7 & 2.90 & 6.29 & 7.40 & 6.34 & 14.0 & 6.47 & 11.0 & 6.41 \\
\hline & & $\mathrm{S} 40 \mathrm{E}$ & 72.5 & 0.7 & & 6.26 & & 6.31 & & 6.44 & & 6.38 \\
\hline \multirow[t]{2}{*}{ IIZ006 } & El Centro 8 & S50W & 49.1 & 1.6 & 3.70 & 6.09 & 28.0 & 6.71 & 30.0 & 6.79 & 10.0 & 6.19 \\
\hline & & $\mathrm{S} 40 \mathrm{E}$ & 61.8 & 1.7 & & 6.19 & & 6.81 & & 6.89 & & 6.29 \\
\hline \multirow[t]{2}{*}{ IIZ007 } & El Centro 5 & S50W & 93.1 & 2.4 & 3.80 & 6.37 & 29.0 & 7.03 & 31.0 & 7.11 & 11.0 & 6.49 \\
\hline & & $\mathrm{S} 40 \mathrm{E}$ & 51.1 & 1.2 & & 6.11 & & 6.77 & & 6.85 & & 6.23 \\
\hline \multirow[t]{2}{*}{ IIZ008 } & E. C. D. ARY & NOOE & 62.6 & 1.4 & 6.30 & 6.22 & 28.0 & 6.82 & 30.0 & 6.90 & 12.0 & 6.34 \\
\hline & & N90W & 55.2 & 1.9 & & 6.17 & & 6.76 & & 6.84 & & 6.28 \\
\hline \multirow[t]{2}{*}{ IIZ009 } & El Centro 4 & $\mathrm{~S} 50 \mathrm{~W}$ & 67.3 & 3.2 & 6.60 & 6.26 & 28.0 & 6.85 & 30.0 & 6.93 & 12.0 & 6.37 \\
\hline & & $\mathrm{S} 40 \mathrm{E}$ & 65.1 & 1.0 & & 6.25 & & 6.83 & & 6.91 & & 6.35 \\
\hline \multirow[t]{2}{*}{ IIZ010 } & Brawley A.P. & $\mathrm{N} 45 \mathrm{~W}$ & 39.6 & 1.3 & 8.60 & 6.07 & 43.0 & 7.06 & 45.0 & 7.10 & 26.0 & 6.54 \\
\hline & & $\mathrm{S} 45 \mathrm{~W}$ & 31.0 & 2.0 & & 5.96 & & 6.95 & & 6.99 & & 6.43 \\
\hline \multirow[t]{2}{*}{ IIZ011 } & Holtville & $\mathrm{N} 45 \mathrm{~W}$ & 36.7 & 2.4 & 8.60 & 6.04 & 21.0 & 6.31 & 24.0 & 6.43 & 8.80 & 6.04 \\
\hline & & $\mathrm{S} 45 \mathrm{~W}$ & 51.9 & 2.5 & & 6.19 & & 6.46 & & 6.58 & & 6.19 \\
\hline \multirow[t]{2}{*}{ IIZ012 } & El Centro 10 & S50W & 36.3 & 2.0 & 8.00 & 6.02 & 28.0 & 6.58 & 31.0 & 6.70 & 13.0 & 6.12 \\
\hline & & $\mathrm{S} 40 \mathrm{E}$ & 53.6 & 1.7 & & 6.19 & & 6.75 & & 6.87 & & 6.29 \\
\hline \multirow[t]{2}{*}{$\Pi Z 013$} & Calexico & $\mathrm{N} 45 \mathrm{~W}$ & 23.7 & 1.4 & 10.0 & 5.88 & 18.0 & 6.04 & 21.0 & 6.12 & 11.0 & 5.90 \\
\hline & & S45W & 27.0 & 0.5 & & 5.93 & & 6.09 & & 6.17 & & 5.95 \\
\hline \multirow[t]{2}{*}{ IIZ014 } & El Centro 11 & S50W & 38.0 & 1.2 & 12.0 & 6.12 & 30.0 & 6.68 & 32.0 & 6.76 & 15.0 & 6.18 \\
\hline & & $\mathrm{S} 40 \mathrm{E}$ & 44.5 & 1.7 & & 6.19 & & 6.75 & & 6.83 & & 6.25 \\
\hline \multirow[t]{2}{*}{ IIZ015 } & El Centro 3 & S50W & 29.2 & 2.1 & 12.0 & 6.01 & 29.0 & 6.53 & 31.0 & 6.61 & 15.0 & 6.07 \\
\hline & & $\mathrm{S} 40 \mathrm{E}$ & 46.5 & 1.6 & & 6.21 & & 6.73 & & 6.81 & & 6.27 \\
\hline \multirow[t]{2}{*}{ IIZ016 } & Parachute & $\mathrm{N} 45 \mathrm{~W}$ & 22.2 & 2.2 & 7.80 & 5.80 & 48.0 & 6.91 & 50.0 & 6.95 & 31.0 & 6.49 \\
\hline & & S45W & 17.5 & 1.3 & & 5.70 & & 6.80 & & 6.84 & & 6.38 \\
\hline \multirow[t]{2}{*}{ IIZ017 } & El Centro 2 & S50W & 22.1 & 1.1 & 15.0 & 5.94 & 32.0 & 6.52 & 34.0 & 6.60 & 18.0 & 6.00 \\
\hline & & $\mathrm{S} 40 \mathrm{E}$ & 47.1 & 1.1 & & 6.27 & & 6.85 & & 6.93 & & 6.33 \\
\hline \multirow[t]{2}{*}{ IIZ018 } & El Centro 12 & S50W & 19.1 & 1.8 & 17.0 & 5.92 & 32.0 & 6.46 & 34.0 & 6.54 & 20.0 & 5.98 \\
\hline & & S40E & 19.8 & 1.7 & & 5.94 & & 6.45 & & 6.56 & & 6.00 \\
\hline IIZ019 & Calipatria & N45W & 13.7 & 1.3 & 18.0 & 5.80 & 57.0 & 6.88 & 58.0 & 6.90 & 41.0 & 6.56 \\
\hline & & S45W & 12.3 & 1.6 & & 5.74 & & 6.83 & & 6.85 & & 6.51 \\
\hline $\mathrm{IIZ020}$ & El Centro 13 & S50W & 12.0 & 1.7 & 20.0 & 5.80 & 34.0 & 6.34 & 36.0 & 6.40 & 22.0 & 5.86 \\
\hline & & $\mathrm{S} 40 \mathrm{E}$ & 20.1 & 1.9 & & 6.00 & & 6.56 & & 6.62 & & 6.08 \\
\hline IIZ021 & El Centro 1 & S50W & 9.05 & 2.0 & 21.0 & 5.70 & 35.0 & 6.21 & 37.0 & 6.30 & 24.0 & 5.82 \\
\hline & & S40E & 14.5 & 1.6 & & 5.90 & & 6.46 & & 6.50 & & 6.02 \\
\hline IIZ022 & Superstition & $\mathrm{S} 45 \mathrm{E}$ & 7.43 & 0.8 & 16.0 & 5.49 & 58.0 & 6.63 & 59.0 & 6.65 & 42.0 & 6.31 \\
\hline & & $\mathrm{N} 45 \mathrm{E}$ & 4.55 & 1.1 & & 5.28 & & 6.42 & & 6.44 & & 6.10 \\
\hline IIZ023 & Plaster City & $\mathrm{S} 45 \mathrm{E}$ & 5.93 & 1.1 & 28.0 & 5.79 & 52.0 & 6.41 & 53.0 & 6.43 & 38.0 & 6.13 \\
\hline & & $\mathrm{N} 45 \mathrm{E}$ & 3.57 & 0.9 & & 5.57 & & 6.19 & & 6.21 & & 5.91 \\
\hline IIZ034 & Niland & N90E & 14.0 & 1.2 & 22.0 & 5.93 & 67.0 & 6.95 & 68.0 & 6.95 & 51.0 & 6.77 \\
\hline & & NOOE & 6.75 & 1.2 & & 5.61 & & 6.63 & & 6.63 & & 6.45 \\
\hline IIZ035 & Westmorland & SOOE & 16.2 & 2.5 & 4.00 & 5.61 & 52.0 & 6.85 & 53.0 & 6.87 & 34.0 & 6.47 \\
\hline & & $\mathrm{N} 90 \mathrm{E}$ & 17.7 & 2.5 & & 5.65 & & 6.89 & & 6.91 & & 6.51 \\
\hline IIZ036 & Meloland & NOOE & 71.4 & 1.7 & 1.20 & 6.25 & 21.0 & 6.59 & 24.0 & 6.71 & 3.00 & 6.25 \\
\hline & & N90W & 84.4 & 2.2 & & 6.33 & & 6.67 & & 6.79 & & 6.33 \\
\hline
\end{tabular}

* Haroun (1980a, b).

$\dagger P P / 2$ denotes $\frac{1}{2}$ of the maximum peak-to-peak amplitude (in meters) of the synthetic WoodAnderson record.

$\ddagger T$ is the approximate period of the Wood-Anderson response at maximum amplitude. 


\section{IMPERIAL VALLEY EARThQUAKe, 15 OCTOBER 1979}

The locations of the strong-motion accelerograph sites used in the study of the Imperial Valley earthquake of 15 October 1979 are shown in Figure 1, along with the epicenter and the observed locations of surface faulting. The data shown in Figure 1 come from three different sources. The epicenter, the location of the faulting, and the majority of the accelerograms recorded in the United States are from the U.S. Geological Survey (Porcella and Matthiesen, 1979). Additional United States data, including free-field motions from the Meloland Overcrossing and the Imperial County Services Building, were made available by the State of California's Office of Strong-Motion Studies (1980). The strong-motion data from Mexico were obtained from the University of California, San Diego (Brune et al., 1979; Brandow and Leeds, 1980). The accelerograms from all these sources were corrected by standard

TABLE 2

Local Magnitude, $M_{L}$, For the 1979 Imperial Valley Earthquake Determined from Strong-Motion Accelerograms-Mexican Data

\begin{tabular}{llcccccccccc}
\hline \multicolumn{1}{c}{ Station } & Component & $\begin{array}{c}P P / 2^{*} \\
(\mathrm{~m})\end{array}$ & $\begin{array}{c}T_{\dagger}^{\dagger} \\
(\mathrm{sec})\end{array}$ & $\begin{array}{c}d_{1} \\
(\mathrm{~km})\end{array}$ & $M_{L_{1}}$ & $\begin{array}{c}d_{2} \\
(\mathrm{~km})\end{array}$ & $M_{L_{2}}$ & $\begin{array}{c}d_{3} \\
(\mathrm{~km})\end{array}$ & $M_{L_{3}}$ & $\begin{array}{c}d_{s} \\
(\mathrm{~km})\end{array}$ & $M_{L_{4}}$ \\
\hline Agrarias & No3E & 48.7 & 1.4 & 1.30 & 6.09 & 3.30 & 6.09 & 12.0 & 6.23 & 19.0 & 6.37 \\
& N87W & 45.2 & 1.6 & & 6.06 & & 6.06 & & 6.20 & & 6.34 \\
Cerro Prieto & S57W & 25.4 & 0.9 & 14.0 & 5.99 & 23.0 & 6.23 & 26.0 & 6.35 & 39.0 & 6.79 \\
& S33E & 17.9 & 0.7 & & 5.83 & & 6.07 & & 6.19 & & 6.63 \\
Chihuahua & N12E & 35.4 & 0.8 & 4.70 & 5.95 & 18.0 & 6.21 & 22.0 & 6.33 & 35.0 & 6.85 \\
Compuertas & N78W & 48.7 & 1.0 & & 6.09 & & 6.35 & & 6.47 & & 6.99 \\
Delta & N75W & 11.3 & 0.6 & 13.0 & 5.61 & 24.0 & 5.91 & 27.0 & 6.03 & 38.0 & 6.47 \\
& N08W & 47.0 & 1.5 & 11.0 & 6.19 & 34.0 & 6.93 & 36.0 & 6.99 & 50.0 & 7.27 \\
Cucapah & S82W & 38.1 & 0.6 & & 6.10 & & 6.84 & & 6.90 & & 7.18 \\
Victoria & N85E & 39.6 & 1.4 & 0.00 & 6.00 & 11.0 & 6.12 & 16.0 & 6.22 & 30.0 & 6.70 \\
& N75E & 8.58 & 1.0 & & & 44.0 & 6.41 & 46.0 & 6.45 & 60.0 & 6.73 \\
Aeropuerto & N15W & 11.6 & 0.8 & & & & 6.54 & & 6.58 & & 6.86 \\
& N00E & 30.1 & 0.9 & 1.40 & 5.88 & 2.30 & 5.88 & 12.0 & 6.02 & 14.0 & 6.06 \\
Mexicali & N90W & 43.5 & 1.4 & & 6.04 & & 6.04 & & 6.18 & & 6.22 \\
& N00E & 28.2 & 0.9 & 8.40 & 5.92 & 9.80 & 5.95 & 16.0 & 6.07 & 14.0 & 6.03 \\
& N90W & 46.9 & 0.6 & & 6.14 & & 6.17 & & 6.29 & & 6.25 \\
\hline
\end{tabular}

* $P P / 2$ denotes $\frac{1}{2}$ of the maximum peak-to-peak amplitude (in meters) of the synthetic WoodAnderson record.

$\dagger T$ is the approximate period of the Wood-Anderson response at maximum amplitude.

procedures (to vol. I stage in Hudson et al., 1969 to 1976) and plotted for examination (Haroun, 1980a, b, and c). After removal of some spike-like errors in some of the digital recordings from Mexico, the accelerograms were used to synthesize WoodAnderson responses according to the procedures given in Kanamori and Jennings (1978). The resulting seismograms are shown in Figure 2. In this figure, the synthetic records are all to the same scales of time and amplitude, and are arranged according to the measure of distance recommended below. It is seen in Figure 2 that the synthetic Wood-Anderson records have amplitudes ranging from over $100 \mathrm{~m}$ down to about $10 \mathrm{~m}$. Relating this with Figure 1 and reports of the damage caused by the earthquake (Brandow and Leeds, 1980), it can be concluded that for this earthquake, potentially damaging motion was associated with Wood-Anderson responses of tens of meters or more, well beyond the range of all standard Wood-Anderson seismographs except the $4 \times$ torsion seismographs. This fact, which also holds for other earthquakes (see Tables 1 to 3 in Kanamori and Jennings, 1978) illustrates the 
extent of the extrapolation involved in estimating characteristics of potentially damaging ground motion from standard seismographic records. The use of synthetic seismograms based on strong-motion accelerograms reduces this extrapolation.

Using the maximum (1/2 peak-to-peak) values of Wood-Anderson response shown in Figure 2, values of $M_{L}$ were determined using four different measures of distance, $\Delta$. The results are shown in Figure 3 , a and b. The four distances used, which are identified on the figure, are: $d_{1}$, the closest distance to the surface trace of the fault; $d_{2}$, the epicentral distance; $d_{3}$, the hypocentral distance; and $d_{4}$, the distance to the center of faulting, usually referred to as the center of energy release. The data shown in Figure 3 are included in Tables 1 and 2.

There is a general trend for the value of $M_{L}$ in Figure 3 to increase with all measures of distance; (except for $d_{1}$ ) this feature will be discussed later in conjunction with the data from several other earthquakes. Concentrating on the trends seen when the different measures of distance are employed, some features can be identified. In the California data, for example, the use of the epicentral or hypocen-

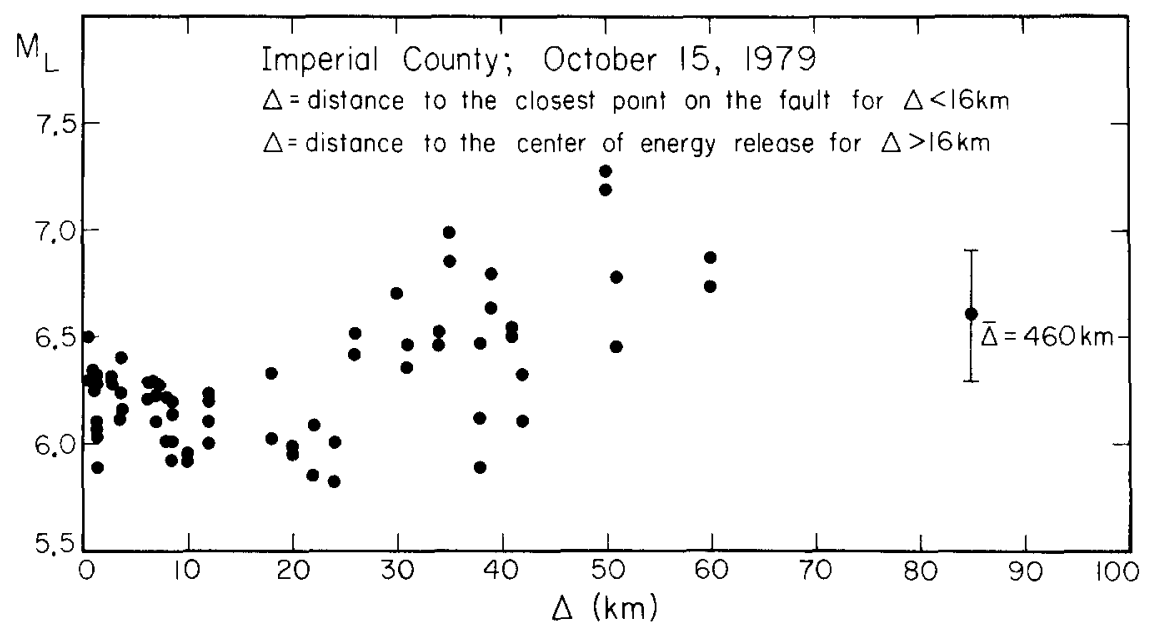

FIG. 4. Values of $M_{L}$ for the Imperial Valley earthquake of 15 October 1979, all stations. The distance used is the closest distance to the fault for stations inside a circle whose diameter $(32 \mathrm{~km})$ is the length of faulting, and whose center is the center of faulting. Outside this circle, $\Delta$ is the distance to the center of the circle. The error bar indicates the standard deviation of the values obtained at seven stations within a distance range from 270 to $610 \mathrm{~km}$.

tral distances, $d_{2}$ or $d_{3}$, leads to a vertical clustering of data near 28 or $30 \mathrm{~km}$. These data points are from the array crossing the fault at El Centro. If the closest fault distance $d_{1}$ is used, or the center-of-faulting distance $d_{4}$, the data from the linear array appears in the near-field, from 0 to $25 \mathrm{~km}$. In this case, the data have less scatter and show a trend to decrease with distance that is believed to be due, in part, to the azimuthal radiation pattern of the shear waves, as the more distant stations are near shear-wave nodal lines, and, in part, to a systematic decrease in $M_{L}$, discussed later. These trends, particularly the vertical stacking of $M_{L}$ for $\mathrm{d}_{3}$ and $d_{2}$, are not seen in the Mexican data, Figure $3 \mathrm{~b}$. Because the epicenter was near the border, as was the closest surface faulting (see Figure 1), the differences in $M_{L}$ as a result of the use of different measures of distance are less significant for the data from Mexico. 
In judging the merits of the different measures of distance, the primary criteria are the consistency of the resulting values of $M_{L}$ and the consistency with the expected radiation pattern of the event. If a physically plausible measure of distance indicated a constant value of $M_{L}$ with increasing distance, with minimal scatter, then the problem would be solved. The situation is not that clear, of course, but our examination of the data led us to conclude that the most consistent results occur if the closest distance to the fault, $d_{1}$, is used for sites within a circle around the center of faulting whose diameter is the length of faulting $(32 \mathrm{~km}$ in the case of the Imperial Valley earthquake). Outside of this circle, the choice of distance is not as critical and the distance to the center of the circle, i.e., the center of faulting, $d_{4}$, is recommended. The values of $M_{L}$ for the Imperial Valley earthquake using this measure of distance are plotted in Figure 4. This figure includes data from both California and Mexico. At a fixed distance, the range of the data is about one-half of a magnitude unit, occasionally more, and there is a tendency for the values of $M_{L}$ to decrease with distance from 0 to about $20 \mathrm{~km}$ and then begin a gradual rise which continues at least to $50 \mathrm{~km}$. The far-field value of $M_{L}$, determined by seismograms with an average distance of $460 \mathrm{~km}$, is consistent with the data from strong-motion instruments in the $30-$ to $60-\mathrm{km}$ range, but is somewhat higher than the near-field value of $M_{L}$ indicated by the strong-motion data.

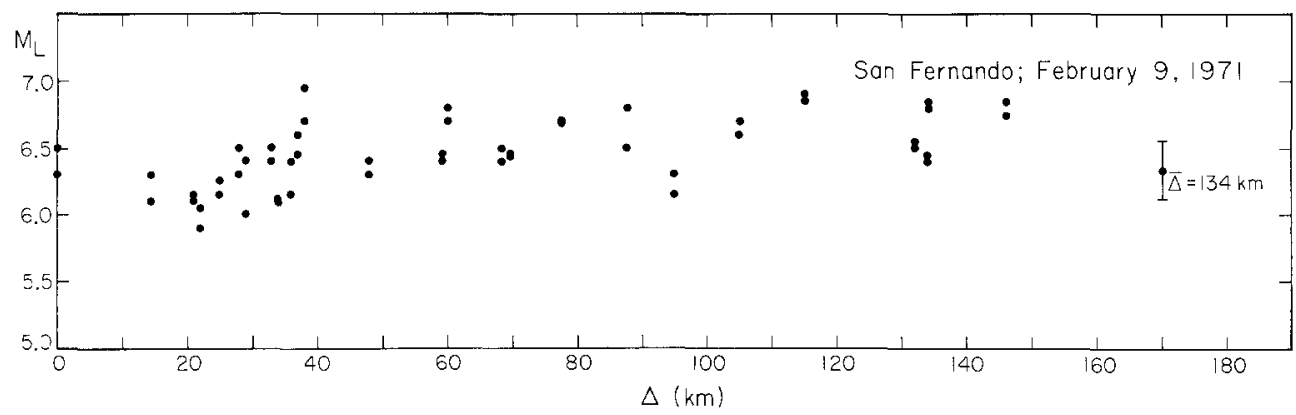

Fig. 5. Values of $M_{L}$ from strong-motion data for the San Fernando earthquake of 9 February 1971. The distance, $\Delta$, is defined in Figure 4. The error bar indicates the standard deviation of the values obtained at four stations within a distance range from 37 to $250 \mathrm{~km}$.

These trends in the data for the Imperial Valley earthquake led us to look for similar trends in data from other earthquakes.

\section{Values of $M_{L}$ From Several Earthquakes}

The values of $M_{L}$ as a function of distance for several earthquakes are shown in Figures 5 through 11. In each case, the same measure of distance was used that was employed in the preparation of Figure 4. In many cases, particularly for more distant records from smaller earthquakes, all common measures of distance give about the same value. The data for these figures are taken from Kanamori and Jennings (1978), with the exception of the San Fernando earthquake for which additional data were prepared.

In the case of the San Fernando earthquake, the data are those included in Table 1 of Kanamori and Jennings (1978) plus the additional data given in Table 3. The additional accelerograms are from those digitized and processed by Hudson et al. (1969 to 1970). A total of 26 accelerograph sites were used. The additional 12 stations were selected to increase, to the extent possible, the data at larger distances and 


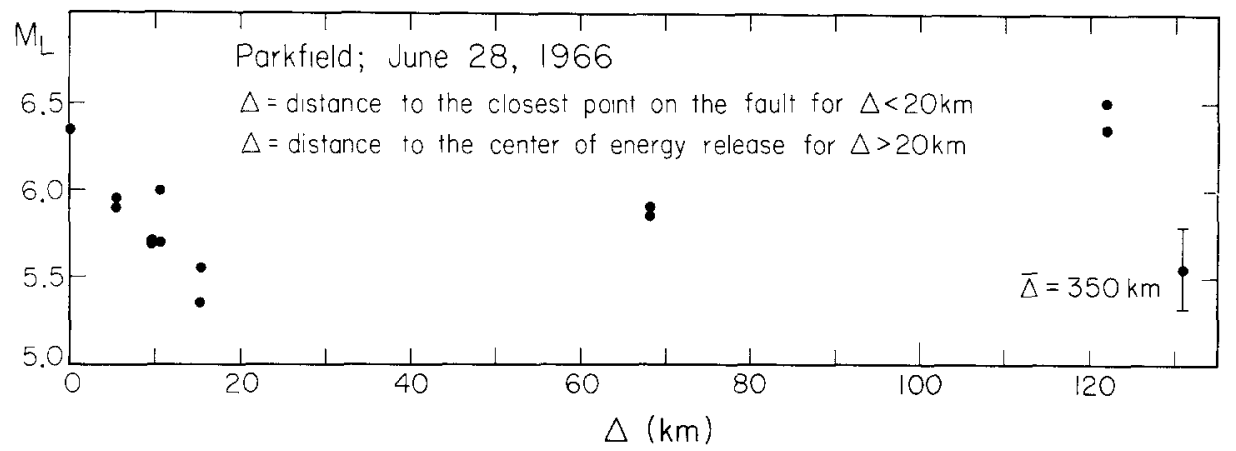

FIG. 6. Values of $M_{L}$ from strong-motion data for the Parkfield earthquake of 28 June 1966. The distance, $\Delta$, is as defined in Figure 4, with the diameter of the circle taken as $40 \mathrm{~km}$. The error bar indicates the standard deviation of the values obtained at four stations within a distance range of 220 to $540 \mathrm{~km}$.

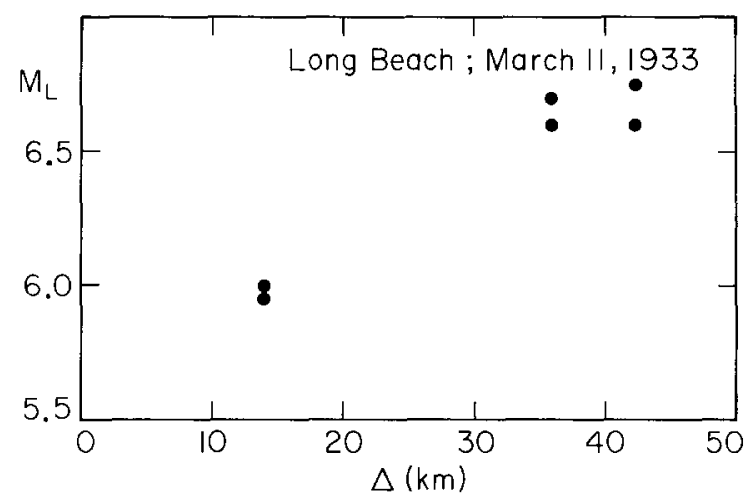

FIG. 7. Values of $M_{L}$ from strong-motion data for the Long Beach earthquake of 11 March 1933. The distance, $\Delta$, is defined in Figure 4.

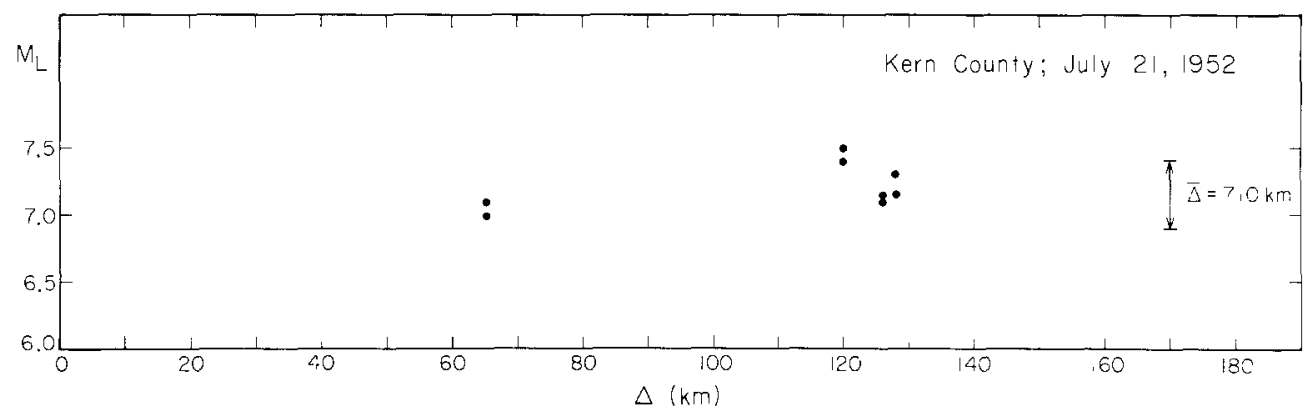

Fig. 8. Values of $M_{L}$ from strong-motion data for the Kern County earthquake of 21 July 1952 . The distance, $\Delta$, is defined in Figure 4 . The range of the two determinations at $\Delta=630$ and $790 \mathrm{~km}$ is indicated by a vertical arrow.

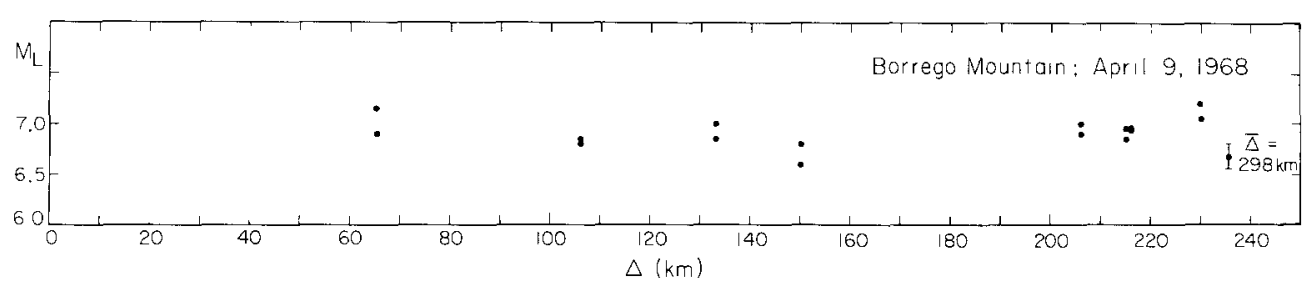

Fig. 9. Values of $M_{L}$ from strong-motion data for the Borrego Mountain earthquake of 9 April 1968. The distance, $\Delta$, is defined in Figure 4 . The error bar indicates the standard deviation of the values obtained at four stations within a distance range of 150 to $430 \mathrm{~km}$. 


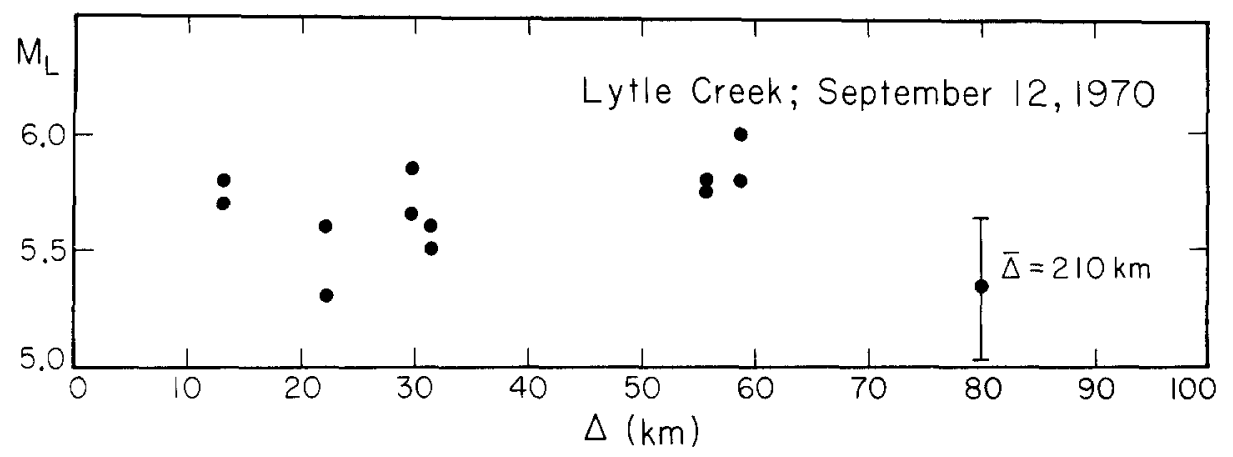

FIG. 10. Values of $M_{L}$ from strong-motion data for the Lytle Creek earthquake of 12 September 1970. The distance, $\Delta$, is defined in Figure 4. The error bar indicates the standard deviation of the values obtained at four stations within a distance range of 70 to $320 \mathrm{~km}$.

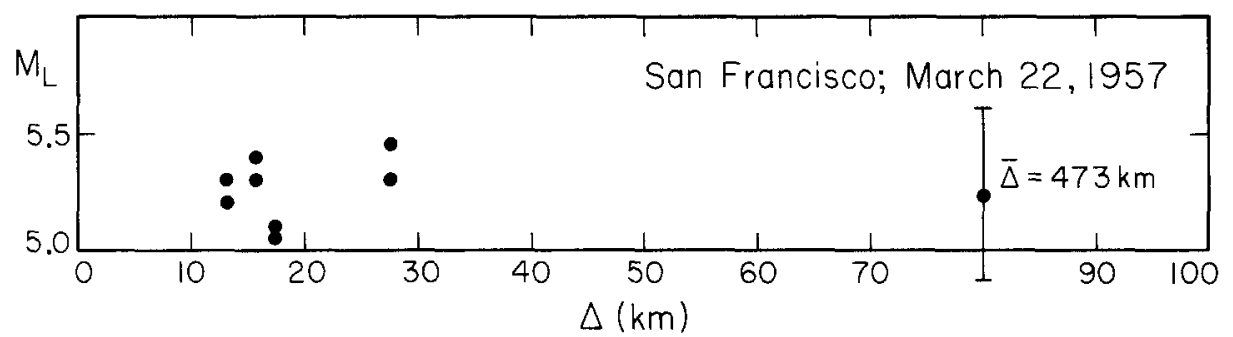

FIG. 11. Values of $M_{L}$ from strong-motion data for the San Francisco earthquake of 22 March 1957. The distance, $\Delta$, is defined in Figure 4 . The error bar indicates the standard deviation of the values obtained at seven stations.

TABLE 3

Local Magnitude, $M_{L}$, for the 1971 San Fernando Earthquake Determined from StrongMotion Accelerograms-Data Additional to Kanamori and Jennings (1978)

\begin{tabular}{|c|c|c|c|c|c|c|}
\hline Station & Ref. No.* & Component & $\Delta(\mathrm{km})$ & $\begin{array}{c}P P / 2 \dagger \\
(\mathrm{m})\end{array}$ & $\begin{array}{c}T \ddagger \\
\text { (sec) }\end{array}$ & $M_{L}$ \\
\hline \multirow[t]{2}{*}{ Carbon Can Dam } & N185 & $\mathrm{S} 50 \mathrm{E}$ & 68.3 & 4.13 & 0.7 & 6.42 \\
\hline & & S40W & & 5.23 & 0.5 & 6.52 \\
\hline \multirow[t]{2}{*}{ Palos Verdes } & N191 & $\mathrm{N} 65 \mathrm{E}$ & 59.2 & 4.16 & 1.5 & 6.40 \\
\hline & & $\mathrm{S} 25 \mathrm{E}$ & & 4.55 & 1.0 & 6.44 \\
\hline \multirow[t]{2}{*}{ Wrightwood } & N183 & N65W & 69.8 & 4.32 & 0.8 & 6.44 \\
\hline & & $\mathrm{N} 25 \mathrm{E}$ & & 4.32 & 0.5 & 6.44 \\
\hline \multirow[t]{2}{*}{ Oso Pump Plant } & F104 & N90W & 60.0 & 7.94 & 1.3 & 6.70 \\
\hline & & NoOE & & 9.16 & 1.4 & 6.77 \\
\hline \multirow[t]{2}{*}{ Costa Mesa } & $\mathrm{P} 220$ & S00W & 8.78 & 3.54 & 1.5 & 6.51 \\
\hline & & $\mathrm{N} 90 \mathrm{E}$ & & 6.88 & 1.0 & 6.79 \\
\hline \multirow[t]{2}{*}{ S.J. Capistrano } & N195 & N33E & 115.0 & 5.88 & 0.7 & 6.87 \\
\hline & & N57W & & 6.40 & 1.1 & 6.91 \\
\hline \multirow[t]{2}{*}{ S. Bernardino } & $\mathrm{O} 206$ & NOOE & 105.0 & 4.52 & 0.8 & 6.71 \\
\hline & & N90E & & 3.64 & 0.8 & 6.61 \\
\hline \multirow[t]{2}{*}{ San Onofre } & $\mathrm{L} 171$ & N57W & 132.0 & 2.27 & 1.2 & 6.56 \\
\hline & & N33E & & 2.08 & 1.4 & 6.52 \\
\hline \multirow[t]{2}{*}{ Port Hueneme } & $\mathrm{P} 222$ & SooW & 77.5 & 6.42 & 2.4 & 6.68 \\
\hline & & S90W & & 6.39 & 1.1 & 6.68 \\
\hline \multirow[t]{2}{*}{ Hemet } & $\mathrm{O} 210$ & S45W & 146.0 & 3.79 & 0.6 & 6.84 \\
\hline & & $\mathrm{S} 45 \mathrm{E}$ & & 2.95 & 0.6 & 6.73 \\
\hline \multirow[t]{2}{*}{ Wheeler Ridge } & E071 & N90E & 96.0 & 1.97 & 1.4 & 6.29 \\
\hline & & SooW & & 1.45 & 0.9 & 6.16 \\
\hline \multirow[t]{2}{*}{ Taft } & P225 & S69E & 134.0 & 1.94 & 1.5 & 6.49 \\
\hline & & $\mathrm{N} 21 \mathrm{E}$ & & 1.86 & 1.6 & 6.47 \\
\hline
\end{tabular}

* Hudson et al. (1969-1976).

$\dagger P P / 2$ denotes $\frac{1}{2}$ of the maximum peak-to-peak amplitude (in meters) of the synthetic WoodAnderson record.

$\ddagger T$ is the approximate period of the Wood-Anderson response at maximum amplitude. 
different azimuths. The sites are plotted on the map in Figure 12, and the values of $M_{L}$ as a function of distance are shown in Figure 5. In examining Figures 4 through 11 , it is seen that the best data sets exist for the Imperial Valley and San Fernando earthquakes. The data from the Parkfield earthquake are less extensive than those from these two earthquakes, but there are more values than for the sparse data that exist for the Long Beach earthquake of 1933, the 1952 Kern County earthquake, and the Borrego Mountain earthquake of 1968. Significant data also exist for the smaller earthquakes of San Francisco, 1957 and Lytle Creek, 1970.

In the better data sets, there is consistent tendency for the value of $M_{L}$ to decrease with increasing distance for approximately the first $20 \mathrm{~km}$, then to rise again. The

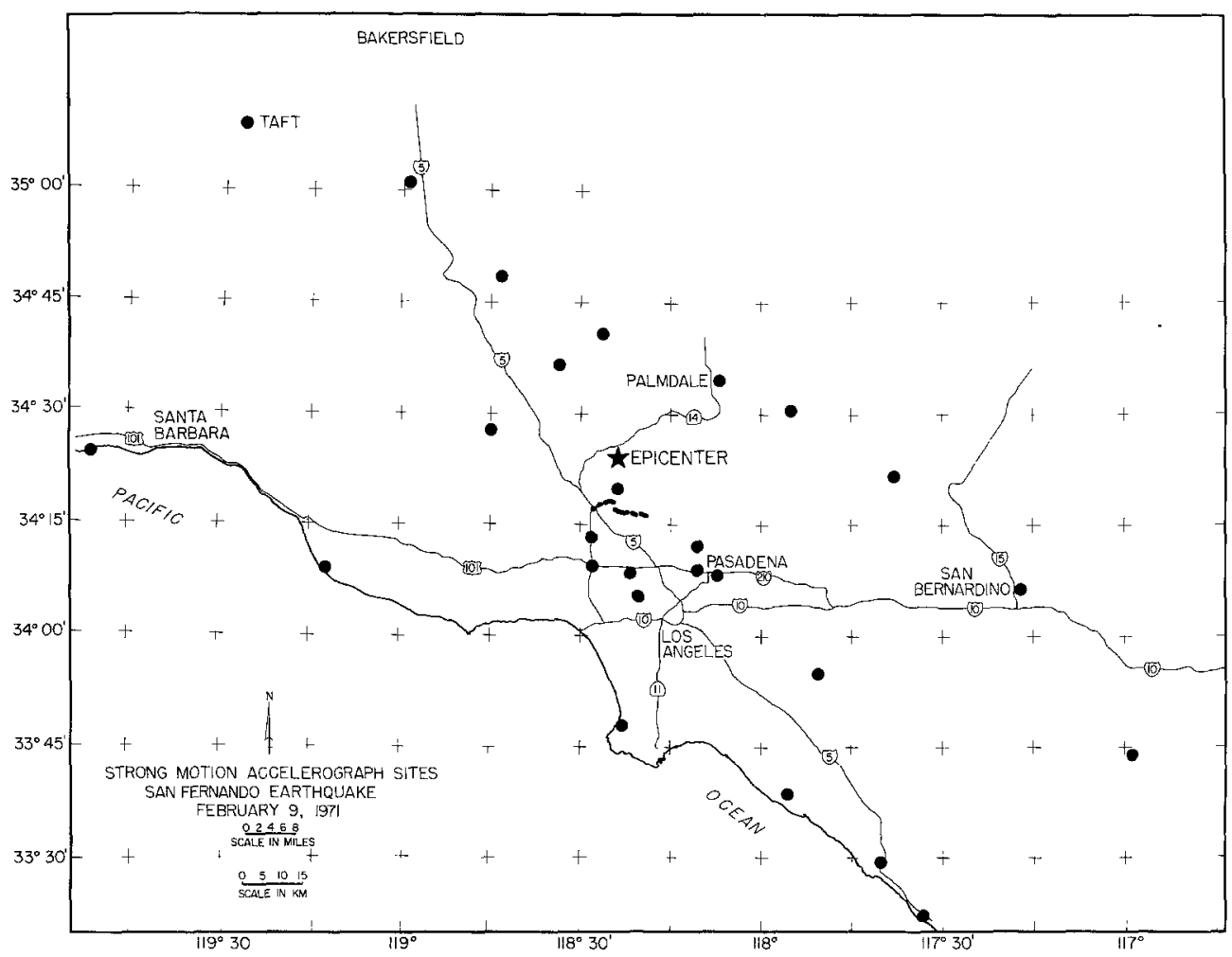

FIG. 12. Location of strong-motion accelerographs used in this study for the San Fernando earthquake of 9 February 1971. The heavy line indicates the surface faulting.

decreasing values of $M_{L}$ in the near-field are most clearly seen in the Imperial Valley and Parkfield data sets, where the trend may be caused, at least partially, by the expected radiation pattern of the shear waves. However, the trend is seen also in the San Fernando data, although it is less pronounced. The tendency of $M_{L}$ to rise for distances greater than $20 \mathrm{~km}$ is seen also in all three data sets. In the case of San Fernando, $M_{L}$ rises to about 6.6 and holds this value out to over $140 \mathrm{~km}$. For the Imperial Valley earthquake, the value of $M_{L}$ also rises to about 6.6 near $50 \mathrm{~km}$, but the trend beyond that distance is not established. The data for Parkfield are very sparse away from the near-field, but they are consistent with the rising trend noted above. It is also interesting to observe in these three sets of data that the value of $M_{L}$ from strong-motion instruments beyond about $30 \mathrm{~km}$ is greater than that found from the far-field seismological instruments. 
The sparser data sets from the other earthquakes, Figures 7 through 11, are discussed next. In general, the data in each case are too meager to establish trends, so these sets of data were examined from the viewpoint of whether the trends seen in data from the Imperial County, San Fernando, and Parkfield earthquakes were consistent with the remaining data. The tendency for $M_{L}$ to decrease in the nearfield to a low around $20 \mathrm{~km}$ and thereafter to rise appears not to be contradicted by the sparse data from these other earthquakes. This is clearly so for the Long Beach data shown in Figure 7. Nor do the Kern County data, although very sparse, contradict this trend. The Borrego Mountain data are more numerous than the
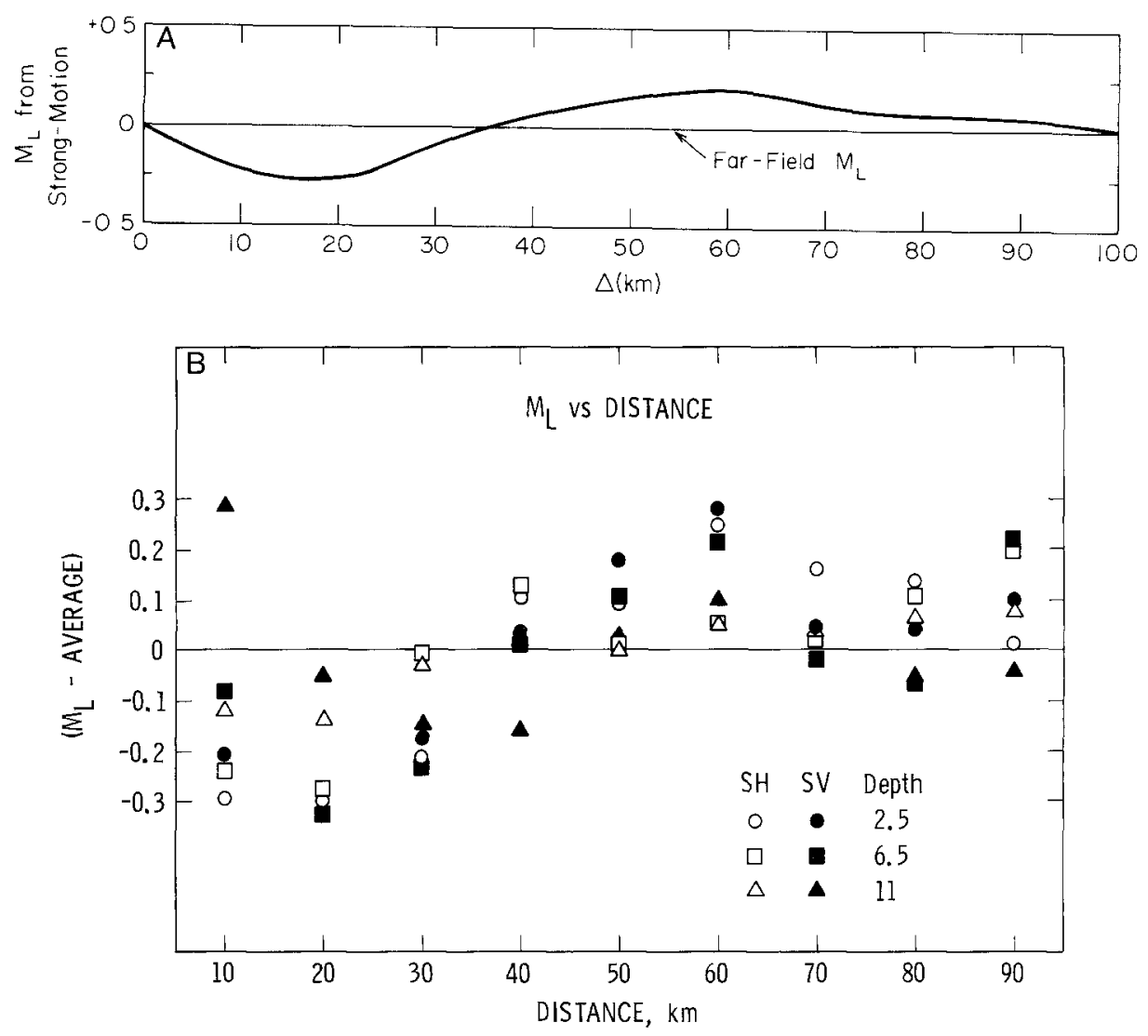

Frg. 13. Trends in values of $M_{L}$ from near-field motion: (A) from the results of this study using strongmotion data; (B) from numerical studies by Hadley et al. (1982).

Kern County data; they show a similar, roughly constant trend in the range beyond $60 \mathrm{~km}$. The data from the smaller earthquakes (Lytle Creek, 1970 and San Francisco, 1957) also are consistent with the trends seen in the three larger data sets; in the case of Lytle Creek, the data are mildly supportive, whereas those from San Francisco, although not contradictory, are not of much significance to the present discussion.

The tendency for the value of $M_{L}$ to decrease with distance to a low point near 20 $\mathrm{km}$ and then to rise at greater distances is clear in those earthquakes where the data are most abundant. In addition, this trend is at least not contradicted by the other 
earthquakes for which the data are less numerous. This leads us to suggest that there is a systematic effect of distance in the values of $M_{L}$ calculated from strong ground motion and that a correction to the commonly used attenuation curves for Wood-Anderson response is warranted. This is particularly the case for engineering applications of local magnitude, wherein $M_{L}$ is often used as a determinant in setting the level of ground motion for design. The nature of the correction thought required is shown in Figure 13a. Using the far-field value of $M_{L}$ as a reference, the correction inferred from the strong-motion data is zero at zero distance, but dips to about $-1 / 4$ unit near 15 to $20 \mathrm{~km}$, then rises gradually to a high point of $+1 / 4$ unit at around 60 to $70 \mathrm{~km}$. The details of the curve shown in Figure 13a, including the approach to zero for distances beyond $70 \mathrm{~km}$, are based both on the strong-motion data and on the desire to have the suggested revision of the attenuation curve used to determine $M_{L}$ be relatively smooth. Based on the strong-motion data alone, it would not be inconsistent to continue the $+1 / 4$ unit correction near $60 \mathrm{~km}$ in Figure

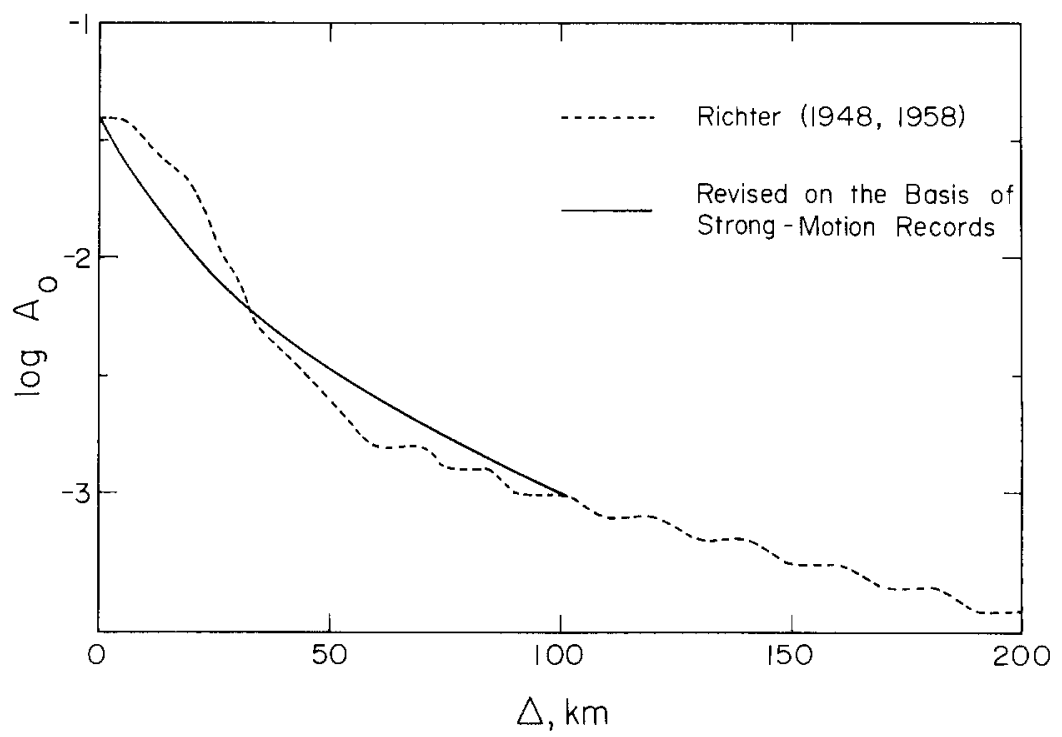

FIG. 14. Revised curve of $\log _{10} A_{0}$ versus $\Delta$ for determination of local magnitude, $M_{L}$. Numerical values of the revision are given in Table 4.

$13 \mathrm{a}$ on out to $100 \mathrm{~km}$ and beyond. This point will have to await data from future earthquakes.

\section{COMPARISON WITH Numerical REsults}

The discussion to this point is based entirely on empirical observations. It is interesting, therefore, to compare our result with that obtained numerically by Hadley et al. (1982). These authors computed theoretical transfer functions of seismic signals for a crustal model appropriate for southern California. They assumed that an accelerogram recorded at a short distance $(\Delta=5.75 \mathrm{~km})$ from the 1975 Horse Canyon, California, earthquake $\left(M_{L}=4.8\right)$ represents the source function of an earthquake. By convolving the calculated transfer function with this source function, a $Q$ function ( $Q_{\beta}=300$ was assumed) and the Wood-Anderson instrument response, they computed $M_{L}$ at various distances. Their results are shown in Figure 13B. Open 
and closed symbols show the results for $S H$ and P-SV components, respectively. Although the value of $M_{L}$ varies considerably depending upon the depth of the source and the wave type, the overall trend is very similar to that which we found empirically. As $\Delta$ increases, the value of $M_{L}$ decreases to a minimum at $\Delta=20 \mathrm{~km}$, and then increases to a maximum at $\Delta=60 \mathrm{~km}$. The range of $M_{L}$ is about 0.5 unit.

\section{Revised Attenuation Curve}

On the basis of our empirical results, as well as the numerical results of Hadley $e t$ al. (1982), we revised Richter's attenuation curve as shown in Figure 14 and Table 4. In view of the various uncertainties involved in the determination of local magnitude, we tried to remove only the average trend in the $M_{L}$ versus $\Delta$ curves

TABLE 4

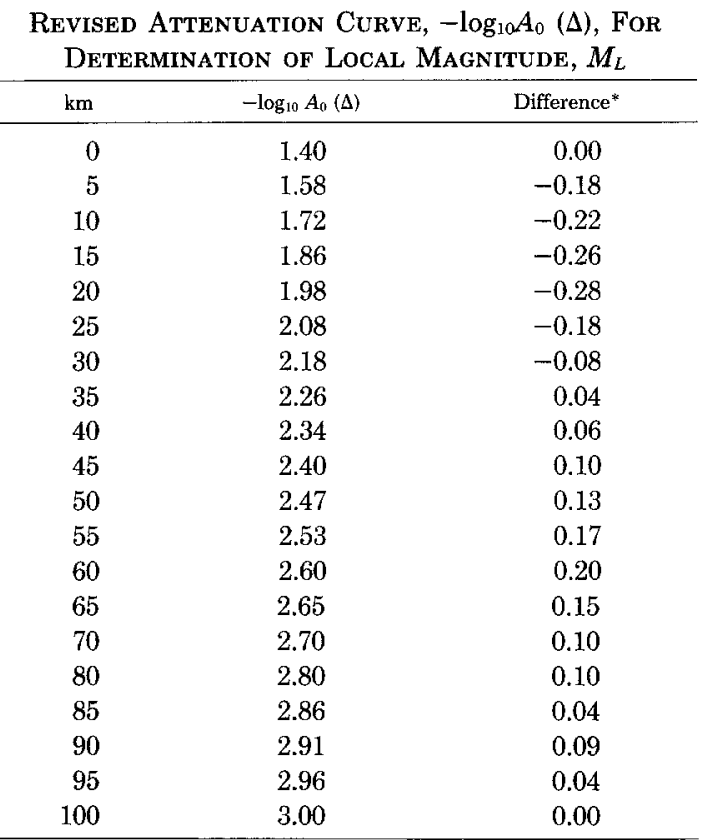

* From the standard attenuation curve [Richter (1935, 1958)] shown in Figure 14

obtained for various earthquakes, rather than the trend observed for any individual event.

\section{Discussion}

There are two major results of the present study. The first relates to the most consistent measure of distance for determination of $M_{L}$ from near-field records and the related problem of the use of distance in estimating the strength of ground motion at a given site in the event of an earthquake of a specified local magnitude. The second problem arises in determining the seismic design criteria for major projects. The data from the Imperial Valley earthquake are particularly well-suited to investigate this question, whereas previous data have been less suitable.

Our investigations led us to conclude that the most consistent results are obtained 
if the closest distance to the surface trace of the fault is used for sites located within a circle whose diameter is equal to the length of faulting, and whose center is the center of faulting. For sites outside of this circle, the measure of distance used is not as critical, but the distance to the center of faulting, the center of the aforementioned circle, is recommended.

The second result concerns the consistency of $M_{L}$, as a function of distance. For sites with $\Delta$ less than about $25 \mathrm{~km}$, the standard Wood-Anderson seismograph goes off-scale, and the values used in the standard attenuation curve are based on the response of the $4 \times$ torsion seismometer, whose properties are different from the standard Wood-Anderson instrument. The strong-motion accelerometer data allow determination of the Wood-Anderson response in the near-field via the use of accurate, synthetic seismograms. The best data sets for examining the variation of $M_{L}$ are from the Imperial Valley, San Fernando, and Parkfield earthquakes. Data from these.earthquakes show that at $\Delta=0$, the value of $M_{L}$ is essentially equal to the far-field value. As $\Delta$ increases, the value of $M_{L}$ drops to about $1 / 4$ unit below this value at a distance near $20 \mathrm{~km}$, then rises to about $1 / 4$ unit higher than the farfield value at around $50 \mathrm{~km}$. Beyond $50 \mathrm{~km}$, the trend is less clear; the values of $M_{L}$ appear to remain high for an appreciable distance. This trend in $M_{L}$ is either mildly supported by, or at least not contradicted by, similar data from several other earthquakes. In addition, it is consistent with numerical results obtained independently by Hadley et al. (1982).

To eliminate this observed trend in the values of local magnitude determined from strong-motion accelerograms recorded in the near-field of major earthquakes, a revised version of the standard attenuation curve, $-\log _{10} A_{0}(\Delta)$, is presented in Figure 14 and Table 4. This revision removes the trend observed from the strongmotion data and smooths the standard curve somewhat in the range $0 \leqq \Delta \leqq 100$ $\mathrm{km}$, the range of the proposed revision.

Using the revised attenuation curve, Heaton (personal communication, 1981) has recalculated the local magnitudes of four major southern California earthquakes. The recalculated values are averages, and use the computed values of WoodAnderson response presented here and in Kanamori and Jennings (1978). The results are: San Fernando, 9 February 1971, 6.4; Imperial Valley, 15 October 1979, 6.4; Borrego Mountain, 9 April 1968, 6.9; and Kern County, 21 July 1952, 7.2. The values are within 0.1 unit of those reported in our 1978 paper; larger changes, up to 0.25 , could be expected when only one or two records are used to determine $M_{L}$.

\section{ACKNOWLEDGMENTS}

The authors wish to acknowledge the assistance of Ronald Pak in making some of the calculations needed for this study.

The financial assistance of the National Science Foundation (Grant PFR-7723687) and the Earthquake Research Affiliates of the California Institute of Technology is gratefully acknowledged.

\section{REFERENCES}

Boore, D. M. (1980). On the attenuation of peak velocity, Proc. of the Seventh World Conf. on Earthquake Engrng., vol. II, Turkish National Committee on Earthquake Engineering, Istanbul, Turkey, 577-584.

Brune, J., J. Prince, F. Vernon, III, E. Mena, and R. Simons (1979). Strong-motion data recorded in Mexico, in Imperial Valley Earthquake of October 15, 1979, U.S. Geol. Surv. Profess. Paper 1254 (in press).

Brandow, G. (Coordinator) and D. J. Leeds (Editor) (1980). Reconnaissance Report, Imperial County, California earthquake, October 15, 1979, Earthquake Engineering Research Institute, 194 pp. 
Espinosa, A. F. (1980). Attenuation of strong horizontal ground accelerations in the western United States and their relation to $M_{L}$, Bull. Seism. Soc. Am. 70, 583-616.

Gutenberg, B. and C. F. Richter (1942). Earthquake magnitude, intensity, energy, and acceleration, Bull. Seism. Soc. Am. 32, 163-191.

Hadley, D. M., D. V. Helmberger, and J. A. Orcutt (1982). Peak acceleration scaling studies, Bull. Seism. Soc. Am. 72, 959-979.

Haroun, M. (1980a). Corrected accelerograms, Imperial Valley earthquake of October 15, 1979, strong motion data recorded by the U.S. Geological Survey, Earthquake Engineering Research Laboratory, California Institute of Technology, Pasadena, California.

Haroun, M. (1980b). Corrected accelerograms, Imperial Valley earthquake of October 15, 1979, recorded motions of the Imperial County Services Building, Earthquake Engineering Research Laboratory, California Institute of Technology, Pasadena, California.

Haroun, M. (1980c). Corrected accelerograms, Imperial Valley earthquake of October 15, 1979, strong motion data recorded in Mexico, Earthquake Engineering Research Laboratory, California Institute of Technology, Pasadena, California.

Hudson, D. E., M. D. Trifunac, and A. G. Brady (1969 to 1976). Analysis of strong-motion accelerograms, vol. I, parts A-Y; vol. II, parts A-Y; vol. III, parts A-Y; vol. IV, parts A-Y; Index vol. (EERL Report No. 76-02), Earthquake Engineering Research Laboratory, California Institute of Technology, Pasadena, California.

Jennings, P. C. and H. Kanamori (1979). Determination of local magnitude, $M_{L}$, from seismoscope records, Bull. Seism. Soc. Am. 69, 1267-1288.

Kanamori, H. and P. C. Jennings (1978). Determination of local magnitude, $M_{L}$, from strong-motion accelerograms, Bull. Seism. Soc. Am. 68, 471-485.

McJunkin, R. D. and J. T. Ragsdale (1980). Compilation of strong-motion data from the Imperial Valley earthquake of 15 October 1979, Preliminary Report 26, Office of Strong-Motion Studies, California Division of Mines and Geology.

Porcella, R. L. and R. B. Matthiesen (1979). Preliminary summary of the U.S. Geological Survey strongmotion records from the October 15, 1979 Imperial Valley earthquake, U.S. Geol. Surv. Open-File Rept. 79-1654, 41 pp.

Richter, C. F. (1935). An instrumental earthquake scale. Bull. Seism. Soc. Am. 25, 1-32.

Richter, C. F. (1948). Publ. Bureau Central Seismologique International, Ser, A 17, 217-224.

Richter, C. F. (1958). Elementary Seismology, W. H. Freeman, San Francisco, 768 pp.

\section{Earthquake Engineering Research Laboratory \\ CALIFORNIA INSTITUTE OF TECHNOLOGY \\ Pasadena, Caltfornia 91125 (P.C.J.)}

\author{
Division of Geological and Planetary \\ SCIENCES \\ California Institute of Technology \\ Pasadena, California 91125 (H.K.) \\ Contribution No. 3782
}

